\title{
The Future of PACE Programs in the United States
}

\author{
Avinash Waikar, Samuel Cappel and Kyle Meguess \\ Southeastern Louisiana University, Hammond, LA 70402, United States \\ Email: awaiker@selu.edu
}

\begin{abstract}
Programs that provide All-Inclusive Care for the Elderly (known as PACE Programs) have been in existence in the United States since the early 1970's. This paper describes these programs, their current environment, why the programs have struggled as well as the challenges faced by them. The programs face additional obstacles with the year 2017 U. S. administration change and the potential repeal of "Obama care" by the U.S. Congress, and/or, possible funding cuts to the PACE programs. It also discusses the PACE Innovation Act and the possible future of the PACE programs in the United States.
\end{abstract}

Keywords: Healthcare, All-Inclusive care, elderly.

\section{Introduction}

It is generally believed that the greatness of a nation is judged by how the nation takes care of the elderly and the poor including the provision of healthcare. Since the advent of Medicare and Medicaid in the U.S., the Federal government, already a major stakeholder in U.S. healthcare has become the dominant authority over the US healthcare system. Government serves not only as a payer but also as a regulator and a provider through public hospitals, local health departments, Veterans Affairs Medical Centers, etc. Although significant strides have been made in healthcare delivery in the US since the great depression, aging of the U.S. population has been a formidable challenge to the country's healthcare system today. The rate of aging is five times the rate of population growth and the aging population requires more complex medical care. This has affected the access to healthcare for many Americans as well as the costs and has forced the government to look at the issues of access, healthcare costs, and quality [11].

Regarding "access to healthcare," a review of the history of healthcare in US reveals that the Social Security Act of 1935 was the most significant social health initiative passed by the U.S. Congress which included the Medicare and Medicaid programs among other healthcare initiatives. Further the Hill-Burton Act of 1946 attempted to improve access to healthcare for Americans by increasing the number and size of healthcare facilities substantially. Later some additional government sponsored programs were designed and introduced in the 1960's to improve access for the older and the low income populations unintentionally ignoring the resulting inflationary costs. Blue Cross plans were also introduced in the late 1960s which effectively improved hospital and healthcare access for the people. These programs were further followed by regulatory attempts to address first the availability, then the price and then the quality. Afterwards in the 1990's the healthcare sector saw the emergence of market-oriented changes, competition and privately organized healthcare systems where the primary goal was to contain costs [11]. One of the initiatives first introduced in the early 1970s to improve access and quality for the older people was the "Programs for All inclusive Care for the Elderly" known as the "PACE" programs. This paper specifically discusses these PACE programs, which are little known but are still in existence. It discusses the concept and the framework of PACE, the history of the PACE programs, the challenges for them in achieving the intended goals and their future.

\section{Pace Framework}

\subsection{What is PACE?}

Sollitto [10] offers the following description of PACE programs in the U.S. He says PACE is an optional benefit under both Medicare and Medicaid that focuses entirely on older people who meet their State's 
standards for nursing home level care. It features comprehensive medical and social services that can be provided at an "adult day health center" in a participant's home, and/or in an inpatient facility. For most patients, these services permit them to continue living at home rather than moving to a long-term care facility.

Thus, PACE Programs act as a patient-centered medical home with the program receiving capitated payments from Medicare and Medicaid (part of the Federal Budget) for the total care of the participants they serve. In effect PACE programs are small provider based insurance companies, and they are at full risk for the cost of the services they provide. A team of PACE doctors, nurses, and other health professionals assess each participant's needs and deliver all services via an integrated health care plan.

The PACE Interdisciplinary team consists of a physician, registered nurse, occupational therapist, physical therapist, licensed clinical social worker, home care coordinator, PACE center director, transportation coordinator, drivers, recreational therapist, nutritionist, and certified nursing assistant. Each of these disciplines assesses the participant and develops a comprehensive care plan that fully outlines the participant's needs and interventions to insure complete care of the physical and psychosocial needs. In addition, quality indicators including immunization rates and readmissions are reported to Centers for Medicare and Medicaid Services (CMS) quarterly for review and discussion.

PACE offers and manages all of the medical, social and rehabilitative services enrollees need to preserve or restore their independence, remain in their homes, and maintain their quality of life. The services include all Medicare and Medicaid services provided by the state. Minimum services that must be provided include (a) adult day healthcare to offer nursing, physical, occupational and recreational therapies, (b) Meals, (c) nutritional and social work counseling, (d) social services such as caregiver training, respite care, support groups, etc., (e) medical care provided by a physician familiar with patient, (f) home health and personal care, (g) prescription drugs, (h) other medical care such as dental, vision, podiatrist, and (i) transportation for medical appointments. An enrollee's initial and ongoing needs are determined by PACE's medical team. The team has frequent contact with the patient so that they can detect subtle changes in the senior's condition and react quickly to changing medical, functional or psychosocial problems [10].

\subsection{PACE Eligibility Requirements and Costs}

Enrollment in the PACE program is voluntary. To be eligible:

The participants must be fifty-five years or older

Be certified as requiring their State's nursing home level of care

Live in the PACE service area, and

Be able to safely live in a community setting with the addition of PACE support at the time of enrollment [10]

Sollitto [10] reported that more than 40,000 elders in the U.S. with significant care needs take advantage of PACE services. About ninety percent of participants are enrolled in both Medicare and Medicaid. Seniors with Medicaid do not have to pay any premium. Medicare patients have to pay a premium. There are no deductibles or co-pays for services approved by PACE team. PACE services can also be paid for privately if a senior does not have Medicare yet or qualify for Medicaid.

\subsection{Brief History of PACE Programs}

In the United States, programs for the All-Inclusive Care of the Elderly (PACE) began in the early 1970's in the Chinatown-North Beach community of San Francisco where the families whose elders had migrated from Italy, China and the Philippines needed long term care services. Due to the cultural preferences of these communities, there was a strong desire to develop a community based alternative to the traditional nursing home care available. Local physicians and community leaders worked together to form a nonprofit corporation, "On Lok Senior Health Services," to create a community based system of care. The term "On Lok," means "peaceful, happy abode" in Cantonese dialect of the Chinese language. It started by providing an "adult day health center" which allowed the caregivers of its participants to work during the day while providing care in their homes at night. Over time, the program added additional components such as an onsite clinic and home health services through demonstration grants and initiatives until this and twenty-one other programs who replicated the model became permanently recognized providers in 1997 
under the American Balanced Budget Act of 1997. This act established PACE (an acronym for Programs for the All-Inclusive Care of the Elderly) as a new provider type under Medicare and Medicaid. [8]

Since 1997 PACE Programs have grown to two hundred and thirty-nine sites in thirty-one states. Due to its status as a Medicare and Medicaid provider, new programs must have the support of the Centers for Medicare and Medicaid Services (CMS) as well as its State's Department of Health and Hospitals (DHH). While CMS readily approves new programs since they are considered Medicare Advantage programs, getting "State support" is a challenge due to Medicaid budgets and the new PACE Program's ability to prove its viability and cost savings for that State. However, it appears that PACE Programs may currently be gaining broader acceptance. For example, the State of Louisiana in the southern United States had two PACE Programs until recently. Prior to 2015, the last Louisiana PACE Program to be approved by the State was "Pace Baton Rouge" opening in 2008. After opening "Pace Baton Rouge", applications were closed by the Louisiana Department of Health and Hospitals to new applicants. Applications in Louisiana were again accepted in 2015 when the third Pace Program was opened in Lafayette as "PACE Lafayette."

\section{Research Observations Regarding Current Environment of PACE}

While PACE Programs are not currently affected by the proposed changes related to the American "Affordable Care Act" (ACA) of 2010, the national conversation has also shed light on the fact that PACE could be a viable model for the long term solutions to healthcare it seeks to establish. For decades through this model, some elderly have been receiving the exact care that the Affordable Care Act seeks to achieve for all Americans. Unfortunately in the current environment of accountable care and patient-centered medical homes that the ACA supports, PACE programs are struggling to continue to expand services due to the limits established by current regulations. Some think that through few simple regulatory changes, the PACE model could be adapted to provide coverage to additional demographic groups in a cost effective and clinically sound way.

Thus, currently there are signs that PACE Programs are gaining wider acceptance. Initially the operation of PACE programs was limited to non-profit organizations by the Centers for Medicare and Medicaid Services - this is no longer the case. In 2014 Mathematica Policy Research, under contract with CMS, conducted a study to address the quality of and access to care for participants in for-profit PACE organizations, while also considering other complications that could arise from the participation of for-profit organization in the PACE program. The study can be found at the website:

https://innovation.cms.gov/files/reports/pace-access-qualityreport.pdf.

Results of this study supported the May 19, 2015 CMS report to Congress stating that for-profit entities are, at least on the federal level, no longer barred from participating in the PACE program solely due to their status as for-profit organizations. The report went on to state that given the need for capital and the infrastructure to be a successful program, there currently is no policy reason to continue excluding for-profit entities from participating. The inclusion of for-profit organizations in state PACE programs will serve to increase access to care for Americans. A consistent State-level approach to "for-profit entry to PACE" will greatly enhance the program overall.

\section{Discussion of the Challenges for Pace Programs}

There are four primary challenges that must be addressed to allow PACE programs to expand into a viable option for patients as change continues to sweep through healthcare.

The first challenge is the dependence on Medicaid funding. While Accountable Care Organizations focus solely on providing population-based outcomes based on strict medical criteria, PACE programs are also accountable for outcomes for the nursing home eligible Medicaid population they enroll [1]. PACE programs need to find a way to continue to provide the services it currently provides while developing new strategies to allow non-Medicaid participants to join the program. In order for a non-Medicaid participant to enroll in the PACE program they must pay the equivalent rate that Medicaid pays, of roughly, in excess of three thousand dollars per month. In order to make PACE a viable option for a non-Medicaid population, regulatory changes will have to be sponsored to change the relationship between the programs and Medicaid. These changes would allow the programs to develop specific services at a reasonable cost to the participant instead of the current "all-inclusive" cost and payment dictated by the states. 
Under the current structure, PACE programs, for example in the State of Louisiana provide Personal care and Supportive services, Transportation, Adult Day Health Care, Nursing Facility Care, Respite care and Caregiver education, assistive devices, Social work services, recreation therapy and any other care needed to maintain overall health of the participant [2]. The Medicaid reimbursement cost of these services is determined as a blended rate of nursing home and community based services provided by other programs through the Louisiana Department of Health and Hospitals. Unfortunately, while other programs services are established by service type; the blended rate is used as a one-size-fits-all price, and prevents potential non-Medicaid participants from enrolling. Inclusion of unnecessary cost leads to a few reports such as the 2007 Mathmatica Policy Research Study that show PACE actually increases the cost to Medicaid for PACE participants [3]. A pilot program called EPAC was designed to allow PACE like services without the constraints of the full Medicaid allowance; this program actually looks more like the "On Lok" program prior to 1997. In the pilot run, it used the same medical home and care coordination model with separate funding sources providing the Medicaid equivalent services. As PACE programs are refined new benefits are being discovered. A recent article in "Gerentologist," [9] states that because of their perceived value and cost savings to Medicaid and Medicare, PACE programs are under increasing pressure to expand the numbers of individuals they serve while simultaneously reducing the overall cost of care. A case was cited involving the Elderhaus PACE Program in Wilmington, North Carolina, which reduced use of acute hospital care and skilled nursing home care while demonstrating that $46 \%$ of their participants improved their level of functional independence and $20 \%$ of participants maintained their level of functional independence. It is felt that the use of a plan of care organized according to standard domains of function and the quantifiable method of documenting improvement in functional health outcomes, represents a critical factor in improved outcomes despite lower use of costly hospital and institutional care.

The second challenge is the requirement that participants leave their current primary care physician and use the PACE physician exclusively. Currently regulation requires that a new enrollee leave their community physician and receive services from the PACE primary care physician at the PACE Center. In many instances, a person has maintained a long-term relationship with their physician and this requirement becomes a deal breaker. There are already a few studies in progress to prove that this requirement is unnecessary to provide comprehensive services and cost savings. In addition, there are pilot programs such as the Wisconsin Partnership Program (WPP) in the State of Wisconsin that compared a typical PACE site to one that allowed participants to continue with their community physicians. The data showed that the program was not as successful in controlling hospital usage as PACE, but suggested additional studies are needed. This model may be necessary in order to provide primary care under a Rural PACE initiative, but is a departure from the current model and its success and support is still in question [4]. Under new rules proposed by the Centers for Medicare and Medicaid Studies on August 16, 2016, local physicians would become eligible for inclusion as members of the PACE team. It remains to be seen if the proposed rules will be approved and put in place.

The third challenge is the reliance on PACE Centers, which do not allow for PACE programs to expand into rural areas where the services are most needed. Rural PACE pilot programs were designed to provide the same services as traditional PACE programs, but allow for variances that would accommodate an expanded service area. Currently PACE sites are constrained by the area of roughly a forty-five minute drive from the center due to the need for transportation of participants to and from the center. With a Rural PACE program, the interdisciplinary team would instead travel to several different areas throughout a large service area and bring care to the participants instead of bringing participants to the care. This requires a waiver from the traditional PACE regulations, but expands the reach of PACE and its care coordination over a much greater area. In 2006, as part of the Deficit Reduction Act of 2005, CMS provided $\$ 7.5$ million in competitive grants for fifteen rural healthcare provider organizations to support development of PACE across rural America.

The fourth challenge is the fact that PACE is currently limited to those fifty-five and older considered elderly who meet nursing home level of care. While the Affordable Care Act focuses on healthcare for all Americans, PACE is only for the elderly. There have been a few attempts to expand the PACE model to disabled children, chronic care populations, veterans and nursing home bound populations, but there have been no efforts at all to provide care to other patient populations. The model could be potentially extended to all patient groups including those who are young and healthy. The final challenge of course could be the possible repeal of the Affordable Care Act (Obama care) and possible changes to Medicare and Medicaid. 
The endeavor is already under consideration by the new 2017 administration of the newly elected U.S. President.

\section{The Future of PACE Programs in the U.S.}

\subsection{The PACE Innovation Act}

The National PACE Association has continued to work towards allowing PACE Programs to debundle their services and provide services to a broader range of participants. Included in their policy efforts are reducing the age requirement from fifty-five to eighteen and provide care to people who are not nursing home level of care but have significant chronic disease and other impairments. They are also seeking greater operational flexibility through expanded settings and involvement of community physicians. If these items can gain political support resulting in PACE Innovation Act, the challenges previously discussed could be met with new solutions that will insure the ongoing growth of PACE Programs and the use of the medical home model, [8].

\subsection{The Future}

Changes to the overall structure of the PACE model will allow these PACE organizations to continue to provide the current levels of quality care in an environment that recognizes the model as the ideal representation of the Affordable Health Act's goals for providing quality focused care to the entire population with a focus on cost reduction. The future of PACE is in its expertise as care coordinators in whatever population it serves.

With the policy changes that are being championed through the National PACE Association, the future of healthcare would include a team of medical and social professionals assigned to each person who would be responsible for overseeing and discussing the entire healthcare and social needs while communicating directly with patient to insure their understanding, approval and compliance with the plan. While opponents of the model continue to focus on the failure of provider based Health Management Organizations in the past, the cost savings established by coordinated care reducing the duplication of services and focus on preventative care continue to be pointed to as the only way to solve the country's current healthcare crisis.

While it is possible that PACE Programs may not survive in name over the next several years due to the challenges described, we believe that the model has established a blueprint for providing the style of care that will continue to be the focus with or without the Affordable Care Act. The focus may have some commonalities with the European model of social healthcare.

\section{References}

1. Bloom, Shawn, "PACE as an Accountable Care Strategy," Healthcare Executive Insight, August 2011.

2. DHH Louisiana Website, PACE Fact Sheet, January, 2017.

3. Foster, Leslie, "The Effects of PACE on Medicare and Medicaid Expenditures," http://www.cms.gov/ Research-Statistics-Data-and-Systems/Statistics-Trends-and-Reports/Reports/downloads/Foster_PACE_2009.p df, August, 2007.

4. Hirth, Victor M.D., "Program of All-Inclusive Care (PACE): Past, Present, and Future," American Medical Directors Association Review, March, 2009.

5. KATC Lafayette Website, "PACE Lafayette facility grand opening." http://www.katc.com/story/29896573/ pace-lafayette-facility-grand-opening, August, 2015.

6. Mathematica Policy Research, https://innovation.cms.gov/files/reports/pace-access-qualityreport.pdf, 2014.

7. National PACE Association Website, "Who, What and Where is PACE?" www.npaonline.org, June, 2017.

8. National PACE Association Website, "Policy changes to Support Expansion, Flexibility and Access," www.npaonline.org, April, 2014. 
9. Segelman, Micah; Xueya Cai; van Reenen, Christine; Temkin-Greener, Helena, "Transitioning From Community-Based to Institutional Long-term Care: Comparing 1915(c) Waiver and PACE Enrollees," Gerontologist, April, 2017.

10.Sollitto, Marlo "PACE Programs Provide Comprehensive Care for Seniors Who need it the Most," http://www.agingcare.com/articles/pace-program-medicaid-medicare-home-care-142557.htm, 2017.

11.Sultz, H and Young, K. "Health Care USA," Jones and Bartlett Publisher, 2012. 